\title{
THE VIBRATORY BEHAVIOUR OF A LATHE WITH CONTINIOUS VARIATOR OF HIGH SPEED AND DYNAMIC ABSORBER
}

\author{
STANESCU, M[arius] M[arinel]; BOLCU, D[umitru]; BAGNARU, D[an] G[heorghe]; \\ MIRITOIU, C[osmin] M[ihai] \& CIUCA, I[on]
}

\begin{abstract}
In this paper, a lathe with continuous variator of high speed and dynamic absorber is studied. The machine, which is a complex system with a great number of freedom degrees, has a corresponding number of freedom degrees, which is why in the dynamic study, there will be taken into account only those vibratory modes that, according to the required precision and the main purpose, have a great influence in the development of the studied vibratory phenomenon. From this case, in this paper, a model with 7 degrees of freedom will be used.

Keywords: vibrations, dynamic absorber, high speed variator, lathe
\end{abstract}

\section{INTRODUCTION}

Machining by turning require the usage of a lathe and it is used, in general, to create cylindrical or conical parts. There are also other processes that can be made on a lathe machine (i.e.: drilling).

In the present paper, we study a lathe with continous variator of high speed and dynamic absorber. In the manufacturing process, the vibrations of the lathe can influence the accuracy of the obtained product. That is why, in some cases, even if the chipping process and parameters are correct, the final product is a spoilage. This is the result of unwanted vibrations that may appear during the chipping operation. The vibrations can also inflence the roughness of the obtained product and can insert errors in geometrical and dimensional tolerances.

There are many other studies of the vibrations in different types of manufacturing machines. For example, Salgado et. al.,2009 [1] made a research regarding the inprocess surface roughness estimation procedure, based on least-sqares suport vector machines. This procedure was proposed for the turning processes. There were adopted the next input informations for the considered system: the chipping parameters (like feed rate, cutting speed or the depth of cut), the cutting tool geometry and features extracted from the vibration signals. The investigation was made experimentally and the obtained results have shown that the considered system can predict surface roughness with high accuracy in a fast and reliable way. We can see that, for the roughness conditions, were taken into account the vibrations that appear during the turning process. Lin et. al., 2006 [2] presented a method for preventing an ill-conditioned wire saw machine to create a unconfirmed product. There was applied the grey relational analysis (GRA), wich is (according to Zhennan et. al., 2012 [3]) a new technique for performing prediction, relational analysis and decision making in many areas. So, in the silicon slicing process, the slicing precision is affected by machine vibrations and the unstable wire knife motion. It is known that, the vibration of machine tools during the manufacturing process can affect the machining accuracy and tools life. That is why this effect must be minimized. In this way, Shin and Wang, 1991[4], have designed an optimal damper to minimize the relative vibration between the cutting tool and workpiece during stable machining. There is presented an optimal design procedure based on a lumped parameter model built by existing experimental and analytical techniques. Other vibrations studies were also made in Băgnaru et. al. 2011, [5]. In that paper, there was made a comparative study between the transversal displacements field of the rod (of straight bar type) of a R(RRT) mechanism, kinematic element with linear elastic behaviour, being in forced vibration and the transversal displacements field of the same bar being in rest and simple supported. In the end, the theoretical and experimental obtained results were compared and were obtained errors under $10 \%$. Another vibrations study was made in Stănescu et. al., 2011 [6]. In that paper there was made a comparison study between the field of the transversal displacements of the connecting rod (of bar type) part of a mechanism $\mathrm{R}$ (RRT), kinematic element that has linear viscoelastic behavior, which is in aleatory vibrations, with the field of the transversal displacements for the same bar, but in rest, considered simply leaning. In the end, the theoretical results were compared with the experimental ones and small errors were obtained (under 10\%).

Starting from the vibration problems during the manufacturing process, we create a mathematical model used to define the vibratory behaviour of a lathe with continous variator of high speed and dynamic absorber. The analyzed machine is a complex system that has a corresponding number of freedom degrees. That is why, in the dynamic study, there will be taken into account only those vibratory modes that, according to the required precision and the main purpose, have a great influence in the development of the studied vibratory phenomenon. For the considered case, presented in this paper, we shall use a model with 7 degress of freedom.

We propose a novelty in the vibration of manufacturing machines, by presenting an own mathematical model which has resulted from the Lagrange formalism. This model is different from any others presented, for example, in Bagnaru et. al., 194[7] and Bagnaru, 2005 [8], Bagnaru and Rinderu, 1998 [9] and Rinderu and Bagnaru, 1996 [10]. The main result 
obtained with this model is: the dimensional precision is determined by the relative displacements that appear in the chipping zone between the cutting tool and the product, and that are a direct consequence of a vibratory phenomenon.

For the future study we shall consider the next researches:

- create an experimental model and make a comparison between the results obtained with the two models and study the errors;

- study the vibrations of the lathe with a finite element software (like Ansys or Abaqus) and make a comparisson between the results obtained with the two models and study the errors;

- create other analytical models and make a comparison between them and study the errors.

- creating more analytical models for other manufacturing machines and compare them with the results presented by other authors.

\section{THE MECHANICAL MODEL}

By taking into account the assumptions made in the introduction part of this paper, we have created and presented in fig. 1 the mechanical model with 7 degrees of freedom of a lathe with continuous variator of high speed and dynamic absorber, considering the case in which all of them have a great influence in the dimensional precision and in the wear of the component parts that compose its subassemblies.

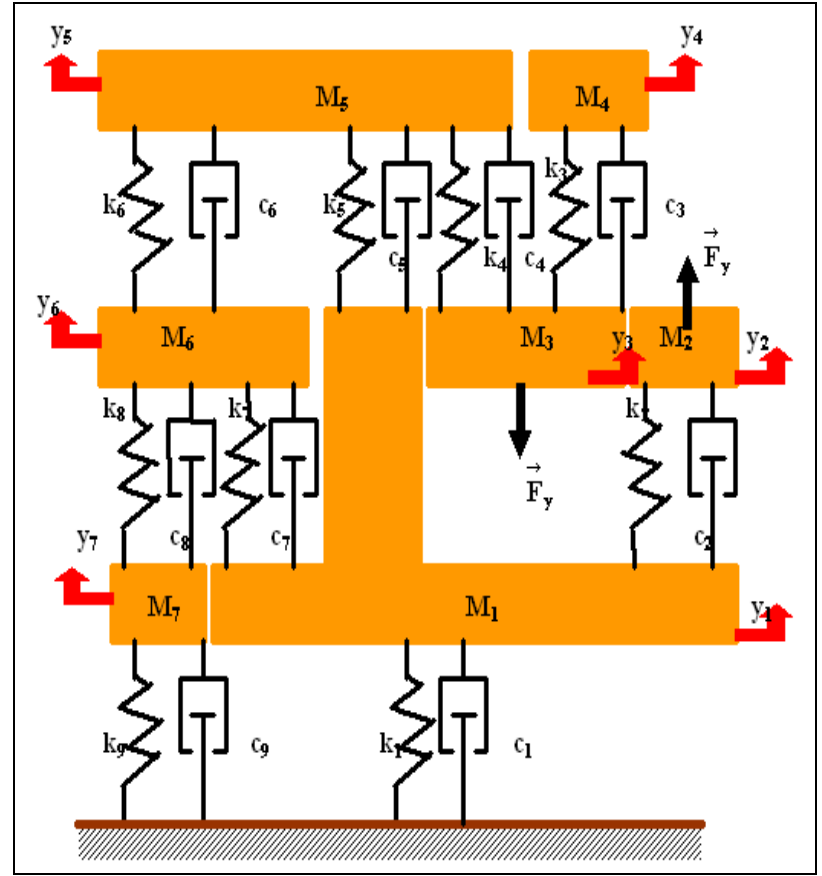

Fig. 1. The mechanical model

In fig. 1 we have marked the next parameters:

- $k_{j}(j=\overline{1,9})$ the elastic constant of the spring;

- $c_{j} \quad(j=\overline{1,9})$ the damping factors.

The other parameters are described in the next subchapter relation (1).

\section{THE MATHEMATICAL MODEL}

The motion mathematical model has resulted from Lagrange's formalism. Because the part elements of the lathe perform vertical oscillating translations, the kinetic energy is

$$
T=\sum_{j=1}^{7} M_{j}{\overrightarrow{v_{c j}}}^{2}=\sum_{j=1}^{7} M_{j} \dot{y}_{j}^{2}
$$

where :

- $M_{1}$ is the body mass;

- $M_{2}$ is the slide rest and the cutter tool mass;

- $M_{3}$ is the product mass;

- $M_{4}$ is the dynamic absorber mass;

- $M_{5}$ is the main shaft mass;

- $M_{6}$ is the mass of the variator of high speed;

$-M_{7}$ is the driving motor mass;

$-q_{j}=y_{j}, j=\overline{1,7}$ are the Lagrange coordinates.

The generalized forces are given by the relations

$$
\begin{aligned}
& Q_{j}=Q_{j, c}+Q_{j, a}+Q_{j, e}=Q_{j, c}= \\
& =-\frac{\partial V}{\partial q_{j}}-\frac{\partial D}{\partial \dot{q}_{j}}+\left\{0, F_{y},-F_{y}, 0,0,0,0\right\}^{T}
\end{aligned}
$$

where:

$$
\begin{aligned}
& V=\frac{1}{2} k_{1} y_{1}^{2}+\frac{1}{2} k_{2}\left(y_{2}-y_{1}\right)^{2}+\frac{1}{2} k_{3}\left(y_{4}-y_{3}\right)^{2}+ \\
& +\frac{1}{2} k_{4}\left(y_{5}-y_{3}\right)^{2}+\frac{1}{2} k_{5}\left(y_{5}-y_{1}\right)^{2}+ \\
& +\frac{1}{2} k_{6}\left(y_{5}-y_{6}\right)^{2}+\frac{1}{2} k_{7}\left(y_{6}-y_{1}\right)^{2}+ \\
& +\frac{1}{2} k_{8}\left(y_{6}-y_{7}\right)^{2}+\frac{1}{2} k_{9} y_{7}^{2} \\
& D=\frac{1}{2} c_{1} \dot{y}_{1}^{2}+\frac{1}{2} c_{2}\left(\dot{y_{2}}-\dot{y}_{1}\right)^{2}+\frac{1}{2} c_{3}\left(\dot{y_{4}}-\dot{y}_{3}\right)^{2}+ \\
& +\frac{1}{2} c_{4}\left(\dot{y_{5}}-\dot{y}_{3}\right)^{2}+\frac{1}{2} c_{5}\left(\dot{y_{5}}-\dot{y}_{1}\right)^{2}+ \\
& +\frac{1}{2} c_{6}\left(\dot{y_{5}}-\dot{y}_{6}\right)^{2}+\frac{1}{2} c_{7}\left(\dot{y_{6}}-\dot{y}_{1}\right)^{2}+ \\
& +\frac{1}{2} c_{8}\left(\dot{y_{6}}-\dot{y}_{7}\right)^{2}+\frac{1}{2} c_{9} \dot{y}_{7}^{2} \text {. }
\end{aligned}
$$

If we give to $\mathrm{j}$ the value 1 , the relation (2) will have the form (3).

$$
\begin{aligned}
& Q_{1}=Q_{1, c}+Q_{1, a}+Q_{1, e}=Q_{1, c}= \\
& =-\frac{\partial V}{\partial q_{1}}-\frac{\partial D}{\partial \dot{q}_{1}}+\left\{0, F_{y},-F_{y}, 0,0,0,0\right\}^{T}
\end{aligned}
$$


where

$-\frac{\partial V}{\partial q_{1}}=k_{2} \cdot\left(y_{2}-y_{1}\right)+k_{5}\left(y_{5}-y_{1}\right)+k_{7} \cdot\left(y_{6}-y_{1}\right)+k_{1} \cdot y_{1}$ $-\frac{\partial D}{\partial \dot{q_{1}}}=c_{1} \dot{y}_{1}+c_{2}\left(-\dot{y_{1}}+\dot{y_{2}}\right)+c_{5}\left(-\dot{y_{1}}+\dot{y_{5}}\right)+c_{7}\left(-\dot{y_{1}}+\dot{y_{6}}\right)$

Similar results are obtained if we insert the other values of $j$ and calculate the factors $Q_{2}, . ., Q_{7}$.

Because the connections system is totally holonom, Lagrange's equations are:

$$
\frac{d}{d t}\left(\frac{\partial T}{\partial \dot{q}_{j}}\right)-\frac{\partial T}{\partial \dot{q}_{j}}=Q_{j}, j=\overline{1,7}
$$

If we give to $\mathrm{j}$ the value 1 , the relation (4) will have the form (5).

$$
\frac{d}{d t}\left(\frac{\partial T}{\partial \dot{q_{1}}}\right)-\frac{\partial T}{\partial \dot{q_{1}}}=Q_{1}
$$

where

$$
\begin{gathered}
\frac{\partial T}{\partial \dot{q}_{1}}=2 \cdot M_{1} \cdot \dot{y}_{1} \\
\frac{d}{d t}\left(\frac{\partial T}{\partial \dot{q_{1}}}\right)=\frac{d}{d t}\left(2 \cdot M_{1} \cdot \dot{y_{1}}\right)=2 \cdot M_{1} \cdot \ddot{y}_{1}
\end{gathered}
$$

If we replace the relation (3) in (5), we will obtain an equation that can have its parameters gouped by the $\ddot{y_{1}}$, $y_{1}$ and $y_{1}$ factors.

Furthermore, by replacing the relations (1) and (2) in the equations system (4), the motion mathematical model is obtained in a matrix way, described in relation (6).

$$
[M]\{\ddot{y}\}+[C]\{\dot{y}\}+[K]\{y\}=\left[Q_{e}\right]
$$

where:

- $[M]$ is the mass matrix;

- $[C]$ is the damping factors matrix;

- $[K]$ is the elastic constant matrix.

While chipping, the disturbing force is considered in this way

$$
F_{y}=F_{0} \mu \frac{a}{a_{0}} \sin \left(\omega_{e} t\right)
$$

where:

- $F_{0}$ is the nominal chipping force;

- $\mu$ is the overlapping factor between the previous and the present cutter tool operation;

$-\frac{a}{a_{0}}$ is the ratio between the real and the nominal depth;

- $\omega_{e}$ is the disturbing force pulsation;

- $V$ is the chipping velocity;

- $l$ is the wavelength of the product undulations;

$-\omega_{e}=\frac{2 \pi V}{l}$.

\section{THE DYNAMIC RESPONSE}

To obtain the dynamic response, the matrix equation (6) is applied the one-sided Laplace transform in relation to time, in homogeneous initial conditions, resulting the below algebraic system, which has the displacements Laplace images $\tilde{y}(s)$ unknown,

$$
\begin{gathered}
{\left[[M] s^{2}+[C] s+[K]\right]\{\tilde{y}(s)\}=} \\
=\frac{\omega_{e}}{s^{2}+\omega_{e}^{2}}\left\{0, F_{0} \mu \frac{a}{a_{0}},-F_{0} \mu \frac{a}{a_{0}}, 0,0,0,0\right\}^{T}
\end{gathered}
$$

Solving the algebraic system (8) and applying the Laplace tranform inverse to the obtained solution, the differential equations system (6) solution results in a symbolic model, described by the relation (9).

$$
\begin{aligned}
& \{y(t)\}=L^{-1}\left[\frac{\omega_{e}}{s^{2}+\omega_{e}^{2}}\left[[M] s^{2}+[C] s+[K]\right]^{-1} .\right. \\
& \cdot\left\{0, F_{0} \mu \frac{a}{a_{0}},-F_{0} \mu \frac{a}{a_{0}}, 0,0,0,0\right\}
\end{aligned}
$$

In the below figures, there are given the variations in terms of time, of those from the displacements of the lathe part elements, such as:

-the body,

-the slide rest and cutter tool,

-the product, or of

-the electric driving motor,

We gave these variations because we have considered that their behaviour is the most important for obtaining a better dimensional precision. 


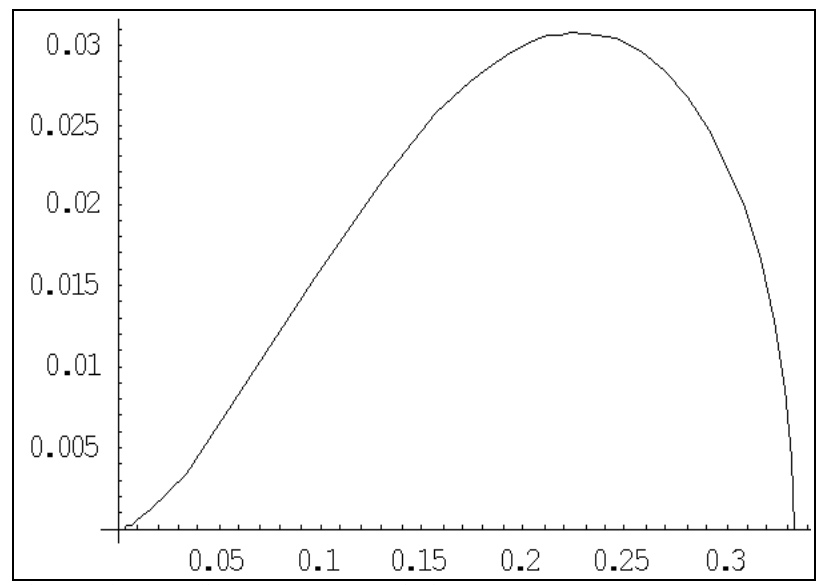

Fig. 2. The coordinate $\mathrm{y}_{1}=\mathrm{y}_{1}(\mathrm{t})$ variation

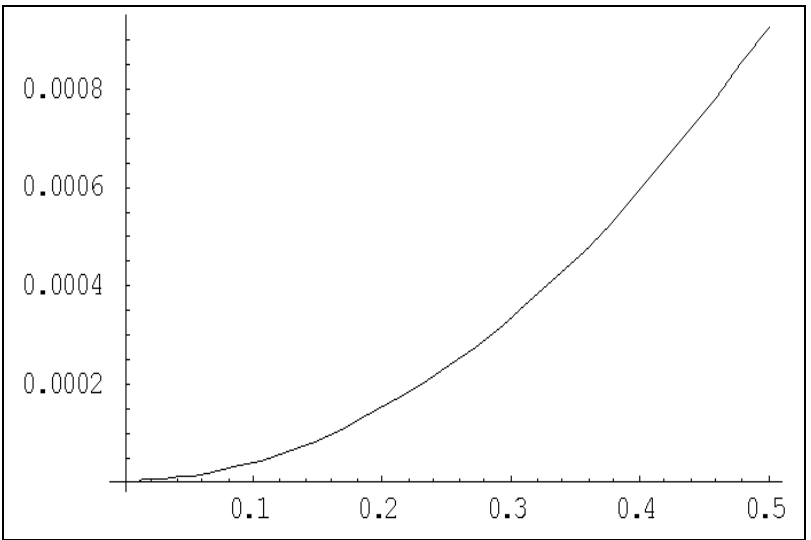

Fig. 3 The coordinate $\mathbf{y}_{\mathbf{2}}=\mathbf{y}_{\mathbf{2}}(\mathbf{t})$ variation

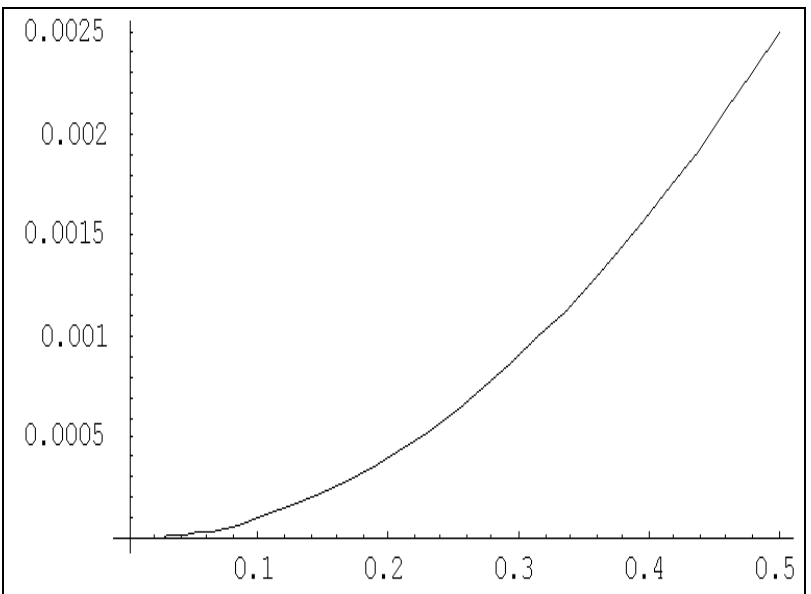

Fig. 4 The coordinate $\mathbf{y}_{\mathbf{3}}=\mathbf{y}_{\mathbf{3}}(\mathbf{t})$ variation

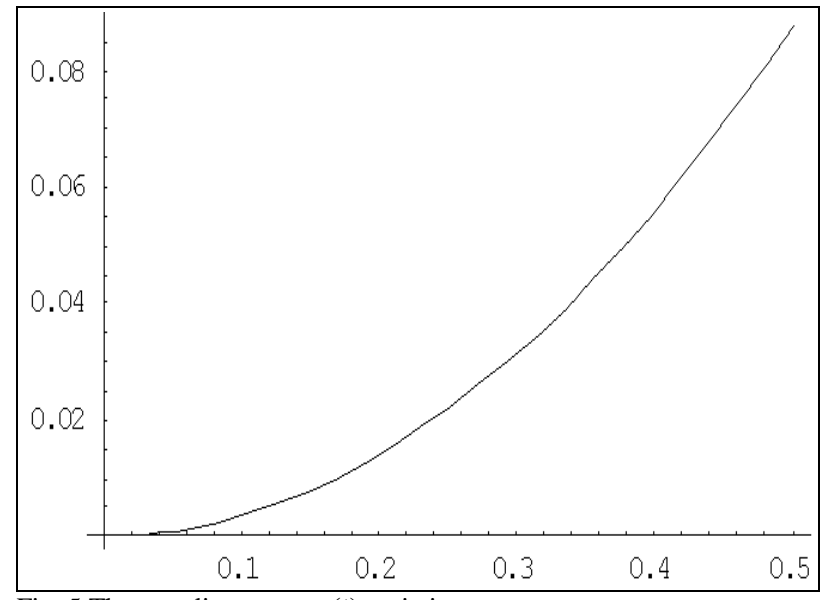

Fig. 5 The coordinate $\mathbf{y}_{7}=\mathbf{y}_{7}(\mathbf{t})$ variation

\section{CONCLUSIONS}

One of the attributes a machine must have is the dimensional precision of the product's area form and quality. The dimensional precision is determined by the relative displacements that appear in the chipping zone between the cutting tool and the product, and that are a direct consequence of a vibratory phenomenon. A way of reducing these displacements is using a dynamic absorber in the chipping zone

\section{REFERENCES}

[1] Salgado, D., R., Alonso, F., J., Cambero, I. \& Marcello, A., (2009), In-process surface roughness prediction system using cutting vibrations in turning, The International Journal of Advanced Manufacturing Technology, Vol. 43, No.1-2, pp. 40-51, DOI: 10.1007/S00170-008-1698-8

[2] Lin, C.-T., Chang C.-W. \& Chen C.-B., (2006), The worst illconditioned silicon wafer slicing machine detected by using grey relational analysis, The International Journal of Advanced Manufacturing Technology, Vol. 31, No. 3-4, pp. 388-395, DOI: 10.1007/S00170-00600685-1

[3] Zhennan, H., Chunbao, L. \& Juhong, L., (2012), Parameter optimization for machined round parts by using grey relational analysis, Advances in Intelligent and Soft Computing, Vol. 137, pp. 441-448, DOI: 10.1007/978-3-642-27866-2_53

[4] Shin, Y., C., Wang, K., W., (1991) Design of an optimal damper to minimize the vibration of machine tool structures subject to random excitation, Engineering with computers, Vol. 7, No. 4, pp. 199-208, DOI: $10.1007 / \mathrm{BF} 01206362$

[5] Băgnaru, D., Stănescu, M., M., Bolcu, D., Miriţoiu, C., M., Rizescu, S., V. \& Diaconu, I., (2011) Comparison Between the Transversal Displacements Field of the Linear Elastic Road of Straight Bar Type Being in Forced Vibration or in Rest, Annals of $D A A A M$ for 2011 \& Proceedings of the $22^{\text {nd }}$ International DAAAM Symposium "Inteligent Manufacturing And Automation : Power Of Knowledge And Creativity”, pp. 281-283, 23-26 ${ }^{\text {th }}$, November, Vienna, Austria

[6] Stănescu, M., M., Băgnaru, D., Bolcu, D., Mirițoiu, C., M., Rizescu, S., V. \& Diaconu, I., (2011), A Comparison Between the Transversal Displacements Fields, of a Linear Viscoelastic Connecting Rod, Which is in Vibration or in Rest Annals of $D A A A M$ for 2011 \& Proceedings of the $22^{\text {nd }}$ International DAAAM Symposium "Inteligent Manufacturing And Automation : Power Of Knowledge And Creativity”, pp. 283-285, 23-26 ${ }^{\text {th }}$, November, Vienna, Austria

[7] Băgnaru, D.; Nanu, Gh. \& Buculei, M. (1984). Mechanical vibrations and machine vibrations, Universitaria, Craiova

[8] Băgnaru, D. (2005). Mechanical Kinematical elements vibration, Sitech, Craiova

[9] Băgnaru, D.; Rinderu, P. (1998). Mechanical systems vibrations, Lotus, Craiova

[10] Rinderu, P.; Băgnaru, D. (1996). Mechanical vibrations- Solved Problems, University of Craiova Publishing House, Craiova 